\title{
Biomassa Tempurung Buah nyamplung (Callophyllum spp) untuk Pembuatan Briket Arang sebagai Bahan Bakar Alternatif
}

\author{
Fahrizal Hazra ${ }^{1}$, Novita Sari ${ }^{2}$ \\ ${ }^{1}$ Departemen Ilmu Tanah dan Sumberdaya Lahan, Faperta - IPB, Jalan Meranti, Kampus IPB \\ Darmaga, Bogor 16680. \\ ${ }^{2}$ Alumni Program Keahlian Analisis Kimia, Program Diploma - IPB
}

\begin{abstract}
Nyamplung shell is a biomass whose existence has not been optimally utilized. Biomass is a solid waste that can be used again as a source of fuel. Favorable characteristics of the biomass is an energy source that can be utilized in a sustainable manner because it is renewable. Biomass of Nyamplung shell can be processed become a form of solid fuel with a same specific dimension, it is resulting from compression of bulk materials, powders, and the relatively small size commonly referred to as charcoal briquettes. The aim of this research is to test the feasibility of nyamplung shell as a raw material for making briquettes on the households by conducting analysis of quality parameters briquette specimens including physical properties (water content, calor value, and density), briquette durability (persistence press), chemical (ash content, fixed carbon and volatile matter content) and the rate of burning charcoal briquette. The treatment in this aim is a mixture composition of raw materials (charcoal of Nyamplung shell) who were given the same amount of adhesive and compressed by compressing hydraulic briquette. The results showed that, charcoal briquettes made from the Calophyllum shell can be used as alternative energy, with a characteristic range of values from 3,39-3,83\% moisture content, calor value ranges from 3.646,14-5.431,35 calories / gram, the range of density values $0,663-0,721 \mathrm{gram} / \mathrm{cm}^{3}$, the range of persistence press value 1,98-5,39 $\mathrm{kg} / \mathrm{cm}^{2}$, the range of ash content value 19,89-24,51\%, the range of fixed carbon value $33,09-40,86 \%$, the range of volatile matter value $35,03-38,57 \%$, and the range of rate of burning from 0,0574-0,0898 grams/second. The low value of moisture content can lead to higher heating value of charcoal briquettes. High/low levels of volatile could affect fast/slow rate of burning charcoal briquettes.
\end{abstract}

Key words : nyamplung shell, biomass, charcoal briquette

\section{PENDAHULUAN}

Seiring dengan pertambahan penduduk dan pertumbuhan industri, penggunaan bahan bakar berupa minyak dapat menyebabkan semakin menipisnya cadangan minyak dunia. Untuk menanggulangi masalah tersebut harus ditemukan suatu energi pengganti yang dapat diperoleh dari sumber-sumber atau bahan-bahan yang siklus pembaharuannya tidak memerlukan waktu yang terlalu lama yang disebut sebagai energi alternatif. Contoh energi alternatif yang digunakan sebagai bahan bakar ialah biomassa.

Tempurung buah nyamplung merupakan salah satu biomassa yang dapat dimanfaatkan sebagai energi alternatif karena merupakan limbah dan belum termanfaatkan secara optimal. Tanaman buah nyamplung termasuk kedalam famili Guttiferae, memiliki nama latin Callophyllum spp. Tanaman buah nyamplung terdiri dari beberapa jenis yaitu $C$. inophyllum Linn, $C$. pulcherrinum Wall., dan $C$. soulatri Burm.f. Tanaman buah nyamplung berupa pohon dengan tinggi mencapai 25-35 meter, dengan panjang bebas cabang sampai 21 meter, dan diameter batang dapat mencapai sekitar $150 \mathrm{~cm}$, batang berdiri tegak dan berbentuk lurus dengan percabangan mendatar, tidak berbanir. Buah nyamplung berbentuk bulat dengan diameter 2,5-3,5 $\mathrm{cm}$, buah muda berwarna hijau, buah tua berwarna kekuningan atau seperti kayu jika sudah dipetik dan dibiarkan lama. Tanaman buah nyamplung memiliki manfaat ganda yaitu kayunya dapat digunakan sebagai kayu komersil, buah (bagian biji) dapa digunakan untuk pembuatan minyak (Heryati, Mile dan Rostiwati, 2007). 


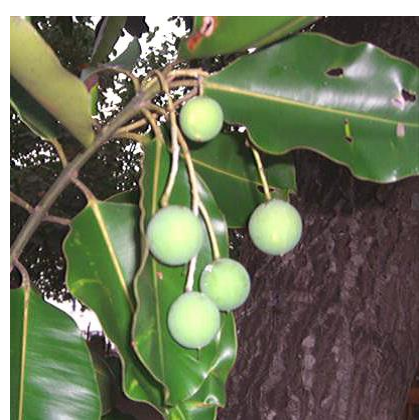

Gambar 1 Buah nyamplung (Heryati, Mile dan Rostiwati, 2007).

Tempurung buah nyamplung yang berasal dari limbah pembuatan minyak nyamplung, akan menjadi masalah lingkungan bila tidak dimanfaatkan secara optimal. Oleh karena itu pemanfaatan limbah tempurung buah nyamplung sebagai bahan baku pembuatan briket arang diharapkan menjadi salah satu peluang pengembangan usaha penanganan limbah yang sejalan dengan inovasi bahan bakar alternatif sehingga selain membantu mengatasi masalah lingkungan, pembuatan briket arang dari tempurung buah nyamplung juga dapat membantu memecahkan masalah menipisnya cadangan bahan bakar minyak.

Penelitian ini bertujuan untuk menguji kelayakan tempurung buah nyamplung sebagai bahan baku briket untuk bahan bakar pada rumah tangga dengan melakukan analisa parameter mutu briket meliputi uji sifat fisika (kadar air, nilai kalor, dan kerapatan), daya tahan briket (keteguhan tekan), kimia (kadar abu, fixed carbon, dan kadar zat mudah menguap) dan laju pembakaran briket arang.

\section{Bahan dan Alat}

\section{METODOLOGI}

Arang tempurung buah nyamplung yang digunakan dalam penelitian ini berasal dari Pusat Penelitian dan Pengembangan Hasil Hutan. Perekat yang digunakan yaitu jenis perekat tapioka. Untuk membentuk briket arang dengan dimensi padat berbentuk kotak, digunakan alat pengempa briket hidrolik sedangkan untuk menguji kualitas dari briket arang tersebut menggunakan oven, tanur, calorimeter bomb, dan universal testing machine.

\section{Metode}

Pelaksanaan percobaan ini meliputi proses pembuatan briket arang tempurung buah nyamplung yaitu: Arang tempurung buah nyamplung yang telah disortasi diayak dengan shieve shaker dengan ukuran $0,500 \mathrm{~mm}$ dan $0,710 \mathrm{~mm}$. Arang tempurung buah nyamplung yang telah diayak disiapkan sebanyak lima jenis, dengan komposisi yang berbeda. Kode I yaitu arang nyamplung ukuran 0,500 mm sebanyak 300 gram. Kode II yaitu arang nyamplung ukuran $0,710 \mathrm{~mm}$ sebanyak 300 gram. Kode III yaitu arang nyamplung ukuran $0,500 \mathrm{~mm}$ dan $0,710 \mathrm{~mm}$ dengan perbandingan $1: 1$ sebanyak 300 gram. Kode IV yaitu arang nyamplung ukuran $0,500 \mathrm{~mm}$ dan $0,710 \mathrm{~mm}$ dengan perbandingan 1:2 sebanyak 300 gram. Kode $V$ yaitu arang nyamplung ukuran $0,500 \mathrm{~mm}$ dan $0,710 \mathrm{~mm}$ dengan perbandingan 2:1 sebanyak 300 gram. Perekat (tapioka) ditambahkan kedalam arang nyamplung sebanyak $5 \%$ dari berat arang. Adonan dicetak dengan alat pengempa hidrolik kemudian briket yang telah jadi dikeringkan dalam oven pada suhu $80^{\circ} \mathrm{C}$ selama tiga hari. 
Pengujian terhadap kualitas briket arang nyamplung yang dihasilkan meliputi analisis sifat fisika (kadar air, nilai kalor, dan kerapatan), daya tahan briket (keteguhan tekan), kimia (kadar abu, fixed carbon, dan kadar zat mudah menguap) dan laju pembakaran briket arang. Dari tiap parameter yang diuji hasilnya dibandingkan dengan kualifikasi briket arang dibeberapa negara seperti Jepang, Amerika, Inggris, dan Indonesia (SNI). Kualifikasi briket arang dibeberapa negara disajikan pada Tabel 1.

Tabel 1. Kualifikasi briket arang di beberapa negara

\begin{tabular}{|c|c|c|c|c|}
\hline Sifat & Jepang & Amerika & Inggris & Indonesia \\
\hline Kadar air ...(\%)... & $6-8$ & 6,2 & 3,6 & 7,57 \\
\hline Kadar abu ...(\%)... & $3-6$ & 8,3 & 5,9 & 5,51 \\
\hline Kadar zat mudah menguap ...(\%)... & $15-30$ & $19-28$ & 16,4 & 16,14 \\
\hline $\begin{array}{l}\text { Kadar karbon terikat (Fixed carbon) } \\
\ldots(\%) \ldots\end{array}$ & $60-80$ & 60 & 75,3 & 78,35 \\
\hline Kerapatan $\ldots\left(\mathrm{g} / \mathrm{cm}^{3}\right) \ldots$ & $1,0-1,2$ & 1 & 0,48 & 0,44 \\
\hline 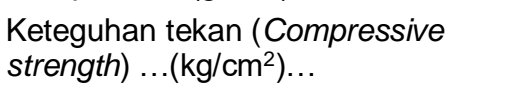 & $60-65$ & 62 & 12,7 & - \\
\hline $\begin{array}{l}\text { Nilai kalor bakar (Calor value) } \\
\text {...(kal/g)... }\end{array}$ & $6.000-7.000$ & 6.230 & 7.289 & 6.814 \\
\hline
\end{tabular}

\section{HASIL DAN PEMBAHASAN}

Briket adalah salah satu cara yang digunakan untuk mengkonversi sumber energi biomassa ke bentuk biomassa lain, yaitu dengan cara biomassa diolah dan dimampatkan sehingga bentuknya menjadi lebih teratur (Hendra, 2008). Kualitas briket arang nyamplung ditentukan berdasarkan pengujian sifat fisik (kadar air, nilai kalor dan kerapatan), kimia (kadar abu, fixed carbon, dan kadar zat mudah menguap), daya tahan briket (keteguhan tekan), dan laju pembakaran briket arang nyamplung.

Briket arang dibuat dengan komposisi ukuran yang berbeda. Kode I yaitu arang nyamplung ukuran $0,500 \mathrm{~mm}$. Kode II yaitu arang nyamplung ukuran $0,710 \mathrm{~mm}$. Kode III yaitu arang nyamplung ukuran $0,500 \mathrm{~mm}$ dan $0,710 \mathrm{~mm}$ dengan perbandingan $1: 1$. Kode IV yaitu arang nyamplung ukuran 0,500 $\mathrm{mm}$ dan $0,710 \mathrm{~mm}$ dengan perbandingan 1:2. Kode $\mathrm{V}$ yaitu arang nyamplung ukuran $0,500 \mathrm{~mm}$ dan $0,710 \mathrm{~mm}$ dengan perbandingan 2:1.

Hasil uji kadar air menghasilkan nilai kadar air yang beragam. Nilai kadar air yang diperoleh masuk kedalam Standar Nasional Indonesi, nilainya yaitu berkisar antara $3,39-3,72 \%$. Besar kecilnya kadar air dari briket arang disebabkan oleh sifat higroskopis arang itu sendiri. Nilai kalor pada berbagai ukuran kode briket arang nyamplung berkisar antara 3.646,14-5.431,35 kal/gram. Tingginya kadar air briket arang nyamplung menyebabkan penurunan nilai kalor (Kardianto, 2009). Hal ini disebabkan karena panas yang tersimpan dalam briket arang nyamplung terlebih dahulu digunakan untuk mengeluarkan air yang ada sebelum kemudian menghasilkan panas yang dapat digunakan sebagai panas pembakaran. 
Tabel 2. Hasil uji sifat fisik, kimia, daya tahan, dan laju pembakaran briket arang nyamplung

\begin{tabular}{|c|c|c|c|c|c|}
\hline \multirow{2}{*}{ Sifat Briket } & \multicolumn{5}{|c|}{ Kode Briket } \\
\hline & 1 & II & III & IV & $\mathrm{V}$ \\
\hline Kadar Air ...(\%)... & 3,83 & 3,39 & 3,52 & 3,67 & 3,72 \\
\hline Nilai Kalor ...(kal/gram). & $3.646,14$ & $5.431,35$ & $4.437,66$ & $4.845,21$ & $4.772,68$ \\
\hline Kerapatan $\ldots\left(\mathrm{g} / \mathrm{cm}^{3}\right) \ldots$ & 0,673 & 0,721 & 0,665 & 0,663 & 0,673 \\
\hline Keteguhan Tekan ...(kg/ $\left.\mathrm{cm}^{2}\right) .$. & 2,8 & 2,24 & 1,98 & 2,25 & 5,39 \\
\hline Kadar Abu ...(\%)... & 24,51 & 19,89 & 22,84 & 22,02 & 23,52 \\
\hline $\begin{array}{l}\text { Kadar Zat Mudah Menguap } \\
\ldots(\%) \ldots\end{array}$ & 38,57 & 35,86 & 35,03 & 38,17 & 36,20 \\
\hline Fixed Carbon ...(\%)... & 33,09 & 40,86 & 38,61 & 36,14 & 36,56 \\
\hline Laju Pembakaran ...(g/detik). & 0,0625 & 0,0820 & 0,0898 & 0,0783 & 0,0574 \\
\hline
\end{tabular}

Rendahnya nilai kerapatan dan keteguhan tekan briket arang tempurung buah nyamplung menunjukan susunan atom karbon yang saling terikat kurang tersusun rapat. Besar atau kecilnya nilai kerapatan briket arang ini dipengaruhi oleh besarnya luas permukaan (pori-pori) dari arang tempurung buah nyamplung yang digunakan. Briket arang tempurung buah nyamplung yang terdiri dari partikel arang yang berukuran kecil akan menghasilkan nilai kerapatan yang besar karena akan diisi oleh lebih banyak perekat yang mengisi pori-pori briket sehingga perbandingan berat per volume (kerapatan) semakin besar pula (Bamgboye A.I dan S. Bolufawi 2010). Tingginya nilai kadar abu pada briket arang nyamplung disebabkan oleh proses karbonisasi yang membuat persentase dari abu meningkat karena abu tidak ikut terlepas pada proses karbonisasi (Nuryana 2009). Tingginya nilai kadar zat mudah menguap ini disebabkan oleh proses karbonisasi yang dilakukan belum sempurna. Besarnya kadar zat mudah mempengaruhi pembakaran (Oladeji, 2010). Semakin tinggi kadar zat mudah menguap pada briket arang maka akan semakin cepat briket arang tersebut terbakar. Rendahnya nilai fixed carbon dari briket arang nyamplung ini selain disebabkan oleh tingginya kadar zat mudah menguap, juga disebabkan oleh tingginya kadar abu dari briket arang nyamplung.

Tabel 2. Data Pengamatan Pengujian Laju Pembakaran Briket Arang Nyamplung

\begin{tabular}{lccccc}
\hline \multirow{2}{*}{ Data Pengamatan } & \multicolumn{5}{c}{ Kode Briket } \\
\cline { 2 - 6 } & I & II & III & IV & V \\
\hline Waktu muncul bara ...(menit)... & 4 & 5 & 7 & 5 & 5 \\
Waktu pembakaran ...(detik)... & 7.380 & 5.280 & 4.320 & 5.400 & 7.200 \\
Asap & +++ & ++ & + & + & +++ \\
Bau asap & Berbau & Berbau & Berbau & Berbau & Berbau \\
Warna asap & Putih & Putih & Putih & Putih & Putih \\
Jumlah air untuk memasak ...(L)... & 6 & 8 & 6 & 8 & 8 \\
\hline
\end{tabular}

Pada saat melakukan uji laju pembakaran, terdapat asap dengan kapasitas yang berbeda yang disebabkan ketika proses pengempaan, tekanan yang digunakan tidak sama yang menyebabkan perpindahan perekat yang masih dalam keadaan cair dari permukaan yang diberi perekat ke permukaan yang belum terkena perekat kurang 
optimal dan bau yang disebabkan oleh perekat yang digunakan (Sudrajat dan Soleh, 1994).

Hasil uji coba briket arang nyamplung sebagai sumber energi alternatif menghabiskan briket sebanyak 520 gram untuk keperluan memasak air sebanyak 6-8 L dengan lamanya proses memasak 72-123 menit. Apabila menggunakan minyak tanah akan menghabiskan 1,5-2 Liter dan bila menggunakan briket arang komersil akan menghabiskan jumlah briket dengan waktu yang sama. Harga per kilogram briket arang komersil ialah Rp 15.000,00 dan tiap bulannya akan menghabiskan 15,6 kg briket sehingga akan membutuhkan Rp $234.000,00$ perbulan untuk memasak. Sedangkan harga per Liter minyak tanah ialah Rp 10.000,00 dan tiap bulannya akan menghabiskan kurang lebih 40 Liter sehingga akan membutuhkan Rp 400.000,00 perbulannya untuk memasak. Dari data ini menunjukan bahwa briket arang nyamplung dapat digunakan sebagai sumber energi alternatif untuk menggantikan minyak tanah, karena bila dihitung dengan harga per kilogram briket arang dan harga per Liter minyak tanah, memasak air menggunakan briket arang nyamplung, akan menghemat sebanyak Rp 166.000,00 tiap bulannya.

Bila dibandingkan dengan penggunaan gas sebagai bahan bakar, briket arang tempurung buah nyamplung ini belum dapat digunakan sebagai pengganti bahan bakar berupa gas karena nilai keuntungannya masih lebih tinggi bila menggunakan gas sebagai bahan bakar. Namun bagi masyarakat yang masih menggunakan minyak tanah sebagai bahan bakar untuk rumah tangga, penggunaan briket arang sebagai bahan bakar pengganti minyak tanah akan optimal karena akan lebih hemat bila menggunakan briket arang tempurung buah nyamplung untuk memasak.

\section{SIMPULAN}

1. Tempurung buah nyamplung dapat digunakan sebagai bahan baku pembuatan briket arang

2. Seluruh ukuran yang dikodekan dalam briket arang nyamplung dapat digunakan sebagai energi alternatif pengganti minyak tanah

3. Kode briket arang nyamplung yang memiliki kualitas paling baik adalah briket arang nyamplung kode II (arang nyamplung ukuran 0,710 mm ) dengan nilai kadar air $3,39 \%$, nilai kalor $5431,35 \mathrm{kal} / \mathrm{gram}$, kerapatan $0,721 \mathrm{gram} / \mathrm{cm}^{3}$, kadar abu $19,89 \%$, fixed carbon $40,86 \%$, diikuti kode $\mathrm{V}$ (arang nyamplung ukuran $0,500 \mathrm{~mm}$ dan 0,710 $\mathrm{mm}$ dengan perbandingan $2: 1$ ) dengan nilai keteguhan tekan $5,39 \mathrm{~kg} / \mathrm{cm}^{2}$, dan nilai laju pembakaran $0,0574 \mathrm{gram} /$ detik.

\section{DAFTAR PUSTAKA}

Bamgboye A.I and S. Bolufawi. 2010. Physical Characteristics of Briquettes from Guinea Corn (sorghum bi-color) Residue. Agricultural Engineering International: the CIGR Ejournal. Manuscript 1364.

Hendra, D. 2008. Briket arang dan arang aktif dari kulit kayu mangium. Prosiding Seminar Teknologi Pemanfaatan Limbah Industri Pulp dan Kertas Untuk Mengurangi Beban Lingkungan. Pusat Penelitian dan Pengembangan Hutan dan Konservasi Alam. Bogor: 58-64.

Heryati, Y., Y. Mile, dan T. Rostiwati. 2007. Upaya penanaman nyamplung (Callophyllum spp) sebagai pohon potensial penghasil HHBK. Jurnal Mitra Hutan Tanaman 2(2) : 35-40. 
Kardianto, P. 2009. Pengaruh variasi jumlah campuran perekat terhadap karakteristik arang briket batang jagung. Skripsi. Fakultas Teknik. Universitas Negeri Semarang. Semarang

Nuryana, F. 2009. Pemanfaatan eceng gondok (Eichornia crassipes) untuk bahan baku briket sebagai bahan bakar alternatif. Skripsi. Fakultas Perikanan dan IImu Kelautan, IPB. Bogor

Oladeji, J.T. 2010. "Fuel Characterization of Briquettes Produced from Corncob and Rice Husk Resides". Pacific Journal of Science and Technology. 11(1) : 101106.

Sudrajat, R., dan S.Soleh. 1994. Petunjuk Teknis Pembuatan Arang Aktif. Badan Penelitian dan Pengembangan Hasil Hutan. Bogor 